\title{
Synthesis and Characterization of Hyperbranched Polymer Having Hole Transporting Ability
}

\author{
Jaekook HA, Hee Cheong LeE, ${ }^{*}$ Sang-Ho LEe,** Noriko KimURA, and Hisaya SATO ${ }^{\dagger}$ \\ Graduate School of Bio-Applications and Systems Engineering (BASE), Tokyo University of Agriculture and Technology, \\ Nakacho 2-24-16, Koganei-shi, Tokyo 184-8588, Japan \\ ${ }^{*}$ Kolon central research park, 207-2, Mabuk-Ri, Guseong-Eup, Yongin-City, Kyunggi-Do, 449-797, Korea \\ ${ }^{* *}$ KISTI, S\&T Cont. Dev. Dept., 52, Eoun-Dong, Yuseong-Gu, Daejeon, 305-806, Korea
}

(Received October 10, 2003; Accepted December 24, 2003)

\begin{abstract}
A hyperbranched polymer (HBP) was prepared by the condensation polymerization of 4-hydroxymethylphenyldiphenylamine (TPA- $\mathrm{CH}_{2} \mathrm{OH}$ ) and was compared with the corresponding linear polymer (LP) prepared by condensation polymerization of 4-methyltriphenylamine (MTPA) and formaldehyde (FA). It was found that the HBP had higher molecular weight with same molecular volume by using gel permeation chromatography (GPC) equipped with low angle laser light scattering (LALLS) and refractive index (RI) detectors. Electronic and optical properties of the two types of polymers were also examined. The two types of polymers showed almost same absorption in the UVvisible region, while HBP showed stronger emission than LP and a new excimer band at $470 \mathrm{~nm}$. The cyclic voltammography showed that $\mathrm{HBP}$ had a redox peak around $1.22 \mathrm{~V}$ versus $\mathrm{Ag} / \mathrm{AgCl}$ electrode, indicating that it has hole transporting ability. HBP is soluble in common organic solvents and forms good quality thin films. Their excellent morphological and thermal stability renders them advantageous for electroluminescence applications.

KEY WORDS Hyperbranched Polymers / Hole Transporting Material / Condensation Polymerization / Triphenylamine / Excimer Emission /
\end{abstract}

Organic charge transporting materials play an important role in many electrical and optical applications such as organic photo conductors (OPC), electroluminescence (EL), and electrochromic devices. ${ }^{1-3}$ The charge transporting materials are divided into two groups: hole and electron transporting materials, abbreviated as HTM and ETM. HTM easily donates electrons to other molecules and possesses positive charge, while ETM tends to receive electrons. HTM is exclusively used as the charge transporting material because of better solubility, higher charge mobility and the ability of form stable radical cations. Almost all HTM are aromatic amine derivatives such as triphenylamine (TPA) and tetraphenyldiaminobenzidine. A significant amount of synthetic effort has been devoted to low molecular weight compounds. ${ }^{4-9}$

Most TPA derivatives are used as vapour deposited thin films, or composite materials dispersed in an inert polymer binder. However, it is difficult to maintain long-term morphological stability due to crystallization or phase seperation. One of the methods to overcome this problem could be the introduction of TPA derivatives into the polymer backbone or into its side chains. ${ }^{10-12}$ Extensive investigations on the polymeric materials have shown the possibility of enhancing device durability due to increased morphological stability. Additionally, the polymeric materials have other advantages, such as good processability and variety of possible chemical modifications.

So far, most of the work reported on polymers has been focused on linear one-dimensional polymers. A few multi-dimensional conjugated polymers, such as hyperbranched polymers (HBP), have been reported to exhibit charge transport and processing properties comparable to their linear counterparts, ${ }^{13-15}$ and multi-dimensional conjugated light emitting polymers have also been discussed in the literature. ${ }^{16,17}$

Among multi-dimensional polymers, dendrimers have attracted considerable attention because of their unique physical and chemical properties. ${ }^{18-21}$ Such dendritic macromolecules are molecular species with a large number of hyperbranched chains of precise length and constitution surrounding a central core. ${ }^{22}$ Dendrimers have a well-defined and perfect branching structure, are non-cross-linked and, in contrast to linear polymers, possess a large number of branching points and endgroups and have to be prepared by multistep reaction requiring time-consuming purification. On the other hand, structurally less-defined HBP can be synthesized in one or two steps, and this could prove an important advantage in practical applications.

In this work, we synthesized a novel hyperbranched polymer composed of TPA units, investigated its electrochemical and optical properties, and applied it to an EL device. 


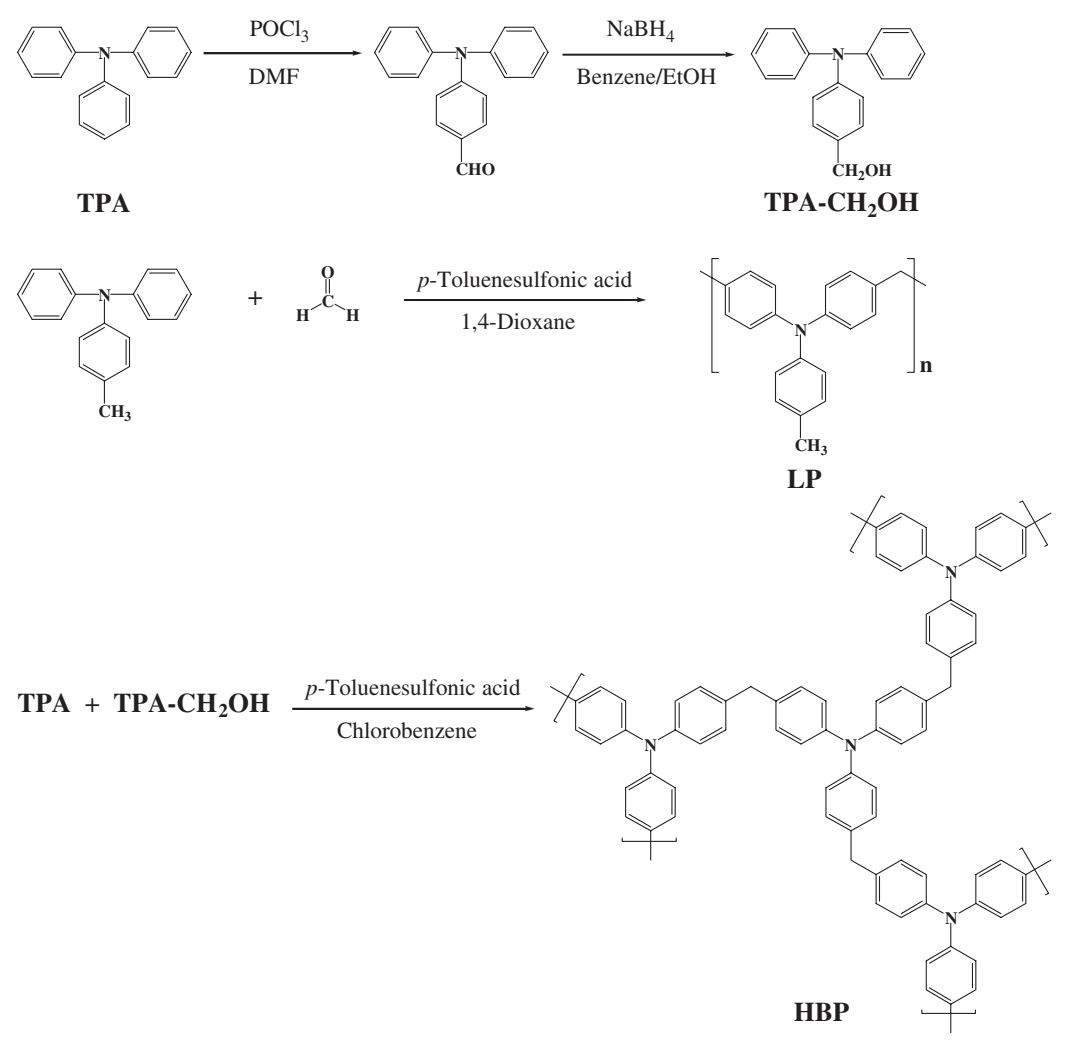

Scheme 1. The syntheses routes of the monomer and polymer.

\section{EXPERIMENTAL}

\section{General}

All the reagents for the synthesis were commercially obtained and were used without further purification unless otherwise noted. Chlorobenzene used as polymerization solvent was distilled over calcium hydride before use. The syntheses routes of the monomer and polymer are shown in Scheme 1.

The monomer, $N$-(4-hydroxymethylphenyl)diphenylamine (TPA- $\mathrm{CH}_{2} \mathrm{OH}$ ), was prepared by the method reported previously. ${ }^{23}$

\section{Optimized Polymerization of Hyperbranched Polymer ( $H B P$ )}

A $50 \mathrm{~mL}$ two-necked round bottomed flask was charged with $0.245 \mathrm{~g}(1 \mathrm{mmol})$ of TPA, $1 \mathrm{~mL}$ of chlorobenzene and $4 \mathrm{~mol} \%$ of $p$-toluenesulfonic acid as a catalyst. A solution of TPA- $\mathrm{CH}_{2} \mathrm{OH}(11 \mathrm{~g}, 40 \mathrm{mmol}$; monomer:core $=40: 1$, molar ratio) dissolved in 30 $\mathrm{mL}$ of chlorobenzene was added by syringe driver at the rate of $3 \mathrm{~mL} / \mathrm{h}$ for the initial $2 \mathrm{~h}$ and $6 \mathrm{~mL} / \mathrm{h}$ for the rest. The reaction temperature was $90^{\circ} \mathrm{C}$. After the complete addition of monomer solution, the stirring was continued for one more hour. The resulting solution was poured into $200 \mathrm{~mL}$ of methanol. The precipitate was filtered and washed with acetone containing small amount of ammonium hydroxide. The
HBP was obtained with the yield of $73 \%$ and dried in vacuum. The polymer without core was synthesized under the same conditions.

As a reference sample, the corresponding linear polymer (LP) was prepared by condensation polymerization of 4-methyltriphenylamine (MTPA) and paraformaldehyde (FA). ${ }^{24}$

\section{Instrumentation and Measurements}

NMR measurements were conducted at $50^{\circ} \mathrm{C}$ with JEOL $\alpha-500$ spectrometer operating at $500 \mathrm{MHz}$ for ${ }^{1} \mathrm{H}$ in $\mathrm{CDCl}_{3}$ with tetramethylsilane (TMS) as an internal standard. The molecular weights of polymers were estimated by gel permeation chromatography (GPC) using a 880-PU pump by JASCO Corp., a column packed with styrene-divinylbenzene gel beads, and a JASCO UV-970 detector. Chloroform was used as an eluent, and the molecular weight was calibrated using polystyrene standards (Shodex by SHOWA DENKO K.K.). In the case of GPC with a low-angle laser-light-scattering (LALLS) detector (KMX 6, Chromatix) and refractive index (RI) detector (Shodex RI 71), the mobile phase was THF. Glass transition temperatures $\left(T_{\mathrm{g}}\right)$ were measured by Rigaku Thermo DSC 8230 instrument at the scan rate of $10 \mathrm{~K} / \mathrm{min}$. The redox potential was measured with cyclic voltammetry in a one-compartment cell with a polarization unit (TOHO PS-06). The measurement was conducted for a film cast on a platinum working electrode in dry 
acetonitrile containing $0.1 \mathrm{M}$ tetra- $n$-butylammonium perchlorate $\left(\mathrm{Bu}_{4} \mathrm{NClO}_{4}\right)$ as an electrolyte under nitrogen atmosphere at the scanning rate of $2 \mathrm{mV} / \mathrm{s}$. Platinum spiral was used as a counter electrode and $\mathrm{Ag} /$ $\mathrm{AgCl}$ as a reference electrode. UV-visible spectra were obtained by a JASCO Ubest-30 UV-VIS spectrometer. Photoluminescence (PL) spectra were measured using JASCO FT-6500 spectrofluorometer.

The EL device used in this study was fabricated by the following method. ITO glass substrates with a sheet resistance of $8 \Omega / \square$ were cleaned by ultra sonic treatment in a detergent solution, de-ionized water, isopropanol, and methanol and then dried with nitrogen gas. EL devices were fabricated with LP or $\mathrm{HBP}$ as hole-transport materials and $\mathrm{Alq}_{3}(50 \mathrm{~nm})$ as electron-transport and emissive material. The polymer dissolved in toluene $(25 \mathrm{mg} / \mathrm{mL})$ was spin coated onto the clean ITO glass substrates. $\mathrm{Alq}_{3}$ layer was fabricated by thermal evaporation at $5 \times 10^{-4} \mathrm{~Pa}$ and cathode (Mg:Ag) at $2 \times 10^{-4} \mathrm{~Pa}$, respectively.

The EL device was operated using a PSR-60M DC power supply by KENWOOD Corp. The current density was measured with an Advantest R5451 auto ranging multimeter and the EL intensity with a LS100 luminance meter by MINOLTA Co., Ltd. All measurements were carried out in air at room temperature.

\section{RESULTS AND DISCUSSION}

\section{Polymerization Results}

HBP was prepared by condensation polymerization of TPA- $\mathrm{CH}_{2} \mathrm{OH}$ with or without core of TPA. When the monomer, TPA- $\mathrm{CH}_{2} \mathrm{OH}\left(\mathrm{AB}_{2}\right.$ type), is added all at once to the reaction medium in the presence of acid catalyst, an important side reaction is intramolecular cyclization which terminates the polymerization by eliminating the focal point of functional group. To compare the effect of presence or absence of core TPA on the condensation polymerization and to research the relationship between feeding rate (reaction time) and molecular weight distribution (MWD), the polymers were synthesized by various monomer feeding rates which were controlled by changing the dropping rate of syringe driver. The results of the polymerization measured by GPC are shown in Tables I and II.

The results of GPC measurement (Table I) showed that slow addition of $\mathrm{AB}_{2}$ monomer to the reaction mixture without core generally lead to higher molecular weight polymers with larger polydispersity (PDI). When the slow monomer addition was carried out in the presence of core molecule, HBP having narrower MWD was obtained as shown in Table II. The number-average molecular weight $\left(M_{\mathrm{n}}\right)$ is almost independent of the presence or absence of the core, and in-
Table I. Results of GPC measurement (polymer without core)

\begin{tabular}{cccc}
\hline $\begin{array}{c}\text { Reaction time } \\
(/ \mathrm{h})\end{array}$ & $\begin{array}{c}M_{\mathrm{n}} \\
\left(/ 10^{3}\right)\end{array}$ & $\begin{array}{c}M_{\mathrm{w}} \\
\left(/ 10^{4}\right)\end{array}$ & PDI \\
\hline 2.5 & 1.63 & 2.54 & 15.6 \\
3.5 & 2.06 & 3.02 & 14.7 \\
4.5 & 2.39 & 3.07 & 12.8 \\
5.5 & 2.42 & 2.94 & 12.1 \\
7.0 & 2.93 & 2.66 & 9.1 \\
\hline
\end{tabular}

Table II. Results of GPC measurement (polymer with core)

\begin{tabular}{cccc}
\hline $\begin{array}{c}\text { Reaction time } \\
(/ \mathrm{h})\end{array}$ & $\begin{array}{c}M_{\mathrm{n}} \\
\left(/ 10^{3}\right)\end{array}$ & $\begin{array}{c}M_{\mathrm{w}} \\
\left(/ 10^{4}\right)\end{array}$ & PDI \\
\hline 2.5 & 1.15 & 0.64 & 5.6 \\
3.5 & 2.08 & 1.04 & 5.0 \\
4.5 & 2.36 & 1.18 & 5.0 \\
5.5 & 2.52 & 1.21 & 4.8 \\
7.0 & 2.78 & 1.38 & 5.0 \\
\hline
\end{tabular}

creases with reaction time for both types of polymers. The weight-average molecular weight $\left(M_{\mathrm{w}}\right)$, on the other hand, increases with reaction time for the polymer with core but reaches a maximum value at an intermediate reaction time for the polymer without core. The PDI of the polymer without core showed a decreasing tendency with increasing reaction time. Additional narrowing of PDI could be obtained for the polymer with core when the monomer was added slowly enough to keep its concentration very low so that it could only react with the polymer already formed on the core but not with each other. In our preparation, monomer TPA- $\mathrm{CH}_{2} \mathrm{OH}$ was added in successive portions to keep the concentration of TPA- $\mathrm{CH}_{2} \mathrm{OH}$ as low as possible, thus enabling reaction only with the end groups of growing chain containing core. Therefore, a reasonable approach to maintain the growth of polymerization is to add the $\mathrm{AB}_{2}$ type monomer slowly to core TPA ( $\mathrm{B}_{3}$ type) solution.

A recent kinetic analysis by Müller et al. showed that the extremely broad MWD could be understood on the basis that each growing chain could couple with another chain. ${ }^{25}$ The rate at which the given polymer chain adds to another chain is proportional to the number of its functional groups, which is identical to its degree of polymerization. Thus, larger molecules will grow faster than smaller ones, giving an additional rise in the PDI. Theoretical works as well as computer simulations had shown that the introduction of core molecules in the synthesis of HBPs leads to considerably lower PDI. ${ }^{25-27}$

\section{GPC Measurement with Two Detectors}

GPC equipped with two detectors (LALLS and RI) provides information on the relationship between molecular volume and molecular size. The LALLS and 


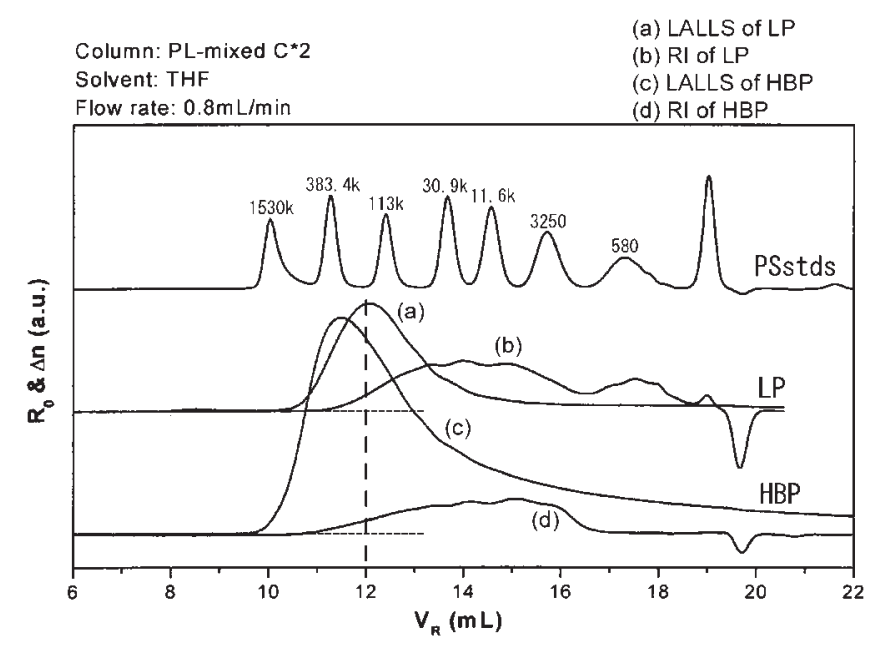

Figure 1. GPC/LALLS and RI traces of LP and HBP: (a) LALLS of LP, (b) RI of LP, (c) LALLS of HBP, and (d) RI of HBP.

RI traces of LP and HBP are shown in Figure 1. The RI signal is proportional to the concentration of the polymer and LALLS signal to the product of molecular weight and concentration of the polymer. At the elution volume of $12 \mathrm{~mL}$, which corresponds to the molecular weight of 150000 with respect to polystyrene, HBP showed about 2 times higher response for LALLS than LP, and about 0.6 times of RI response than LP. These results indicate that HBP had higher molecular weight than LP at the same elution volume, i.e. at the same molecular volume. This is a direct evidence of the hyperbranching effect in the synthesized polymer.

\section{Structural Characterization of $L P$ and HBP}

The structure of LP and HBP was determined by NMR spectroscopy. Figure 2 shows their ${ }^{1} \mathrm{HNMR}$ spectra. According to the chemical shifts of a linear polymer synthesized from TPA and paraformaldehyde, ${ }^{28}$ the signals in the aromatic range around 6.95 to $7.23 \mathrm{ppm}$ can be assigned to the aromatic protons. LP showed two types of aliphatic proton signals at 2.4 and $3.8 \mathrm{ppm}$ which can be assigned to methyl $\left(\mathrm{CH}_{3}\right)$ and methylene $\left(\mathrm{CH}_{2}\right)$ groups. HBP showed only the methylene group signal at $3.8 \mathrm{ppm}$. For both LP and HBP the methylene proton signals were further split into doublets at 3.8 and $3.6 \mathrm{ppm}$ with the intensity ratio of 95:5. It is reported that the signal at $3.8 \mathrm{ppm}$ can be assigned to a methylene proton linked with para position and the signal at $3.6 \mathrm{ppm}$ to a methylene proton linked with meta positions. ${ }^{29}$

Optical Properties Measured by UV-Vis and PL Measurements

Figure 3 shows UV absorption spectra of LP and HBP in toluene solution. The UV spectra are similar,
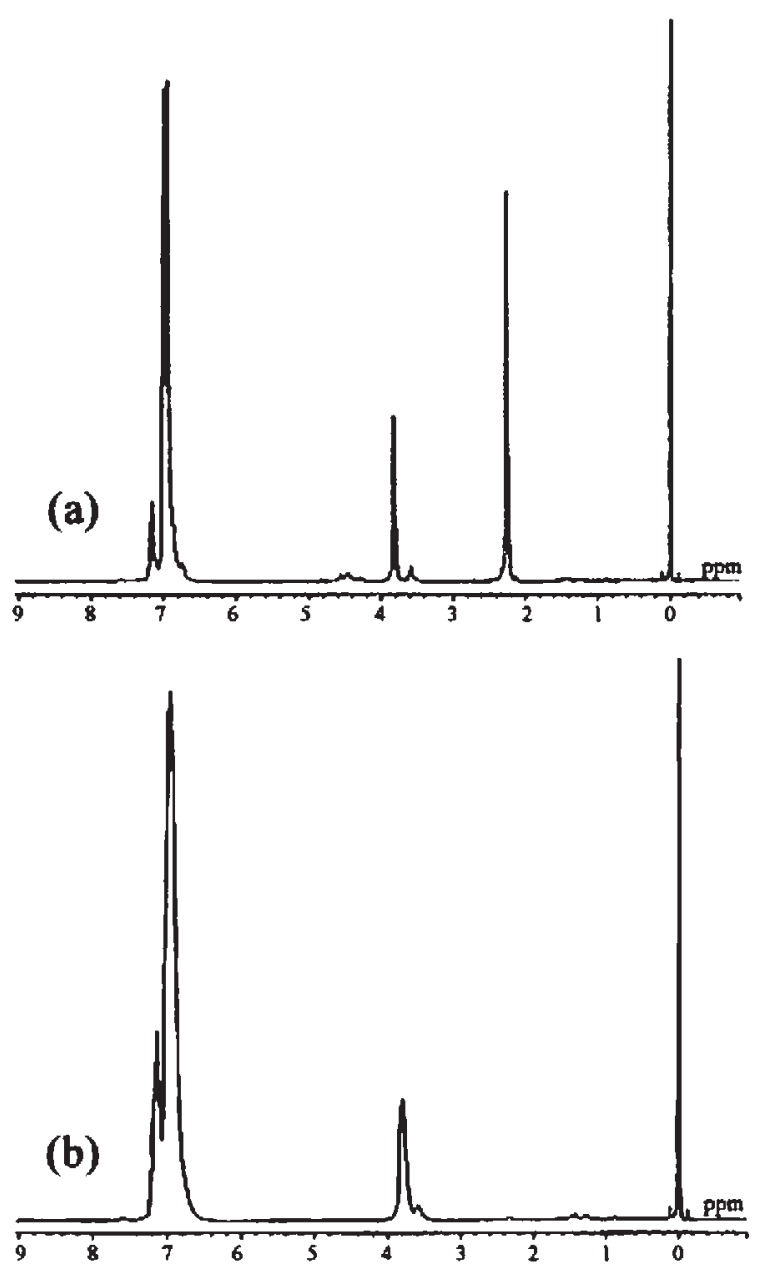

Figure 2. ${ }^{1} \mathrm{H} N M R$ spectra of LP and HBP: (a) LP, and (b) HBP.

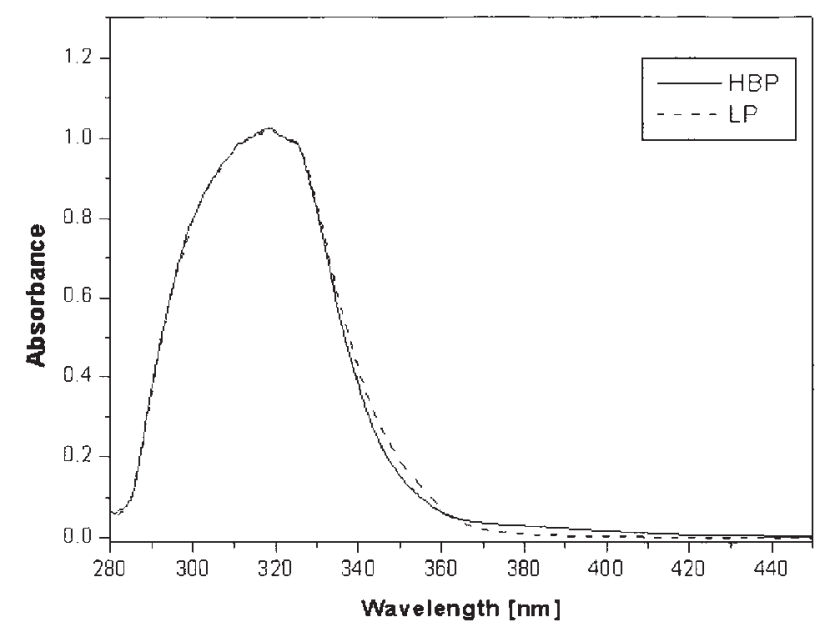

Figure 3. UV absorption spectra of LP and HBP dissolved in toluene at the concentration of $0.01 \mathrm{~g} / \mathrm{L}$.

with an absorption maximum at $319 \mathrm{~nm}$. In addition, HBP exhibits a small tail in the visible region at about $380 \mathrm{~nm}$. The cut-off wavelengths are at $360 \mathrm{~nm}$ $(-3.5 \mathrm{eV})$.

Figure 4 shows the PL emission spectra of HBP and LP (excitation at $319 \mathrm{~nm}$ ) dissolved in toluene at var- 

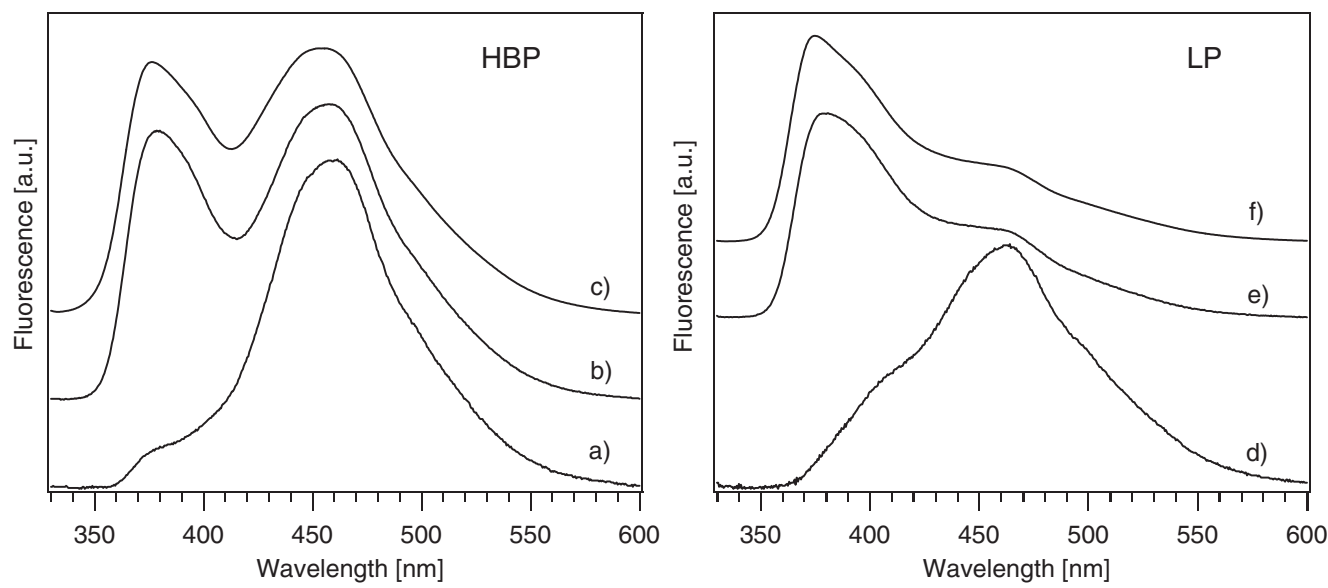

Figure 4. PL emission spectra of LP and HBP dissolved in toluene with various concentration: (a) to (c) are HBP and (d) to (f) are LP; (a) and (d) are $1 \mathrm{~g} / \mathrm{L},(\mathrm{b})$ and (e) are $0.1 \mathrm{~g} / \mathrm{L}$, and (c) and (f) are $0.01 \mathrm{~g} / \mathrm{L}$.

ious concentration ranging from $1 \mathrm{~g} / \mathrm{L}$ to $0.01 \mathrm{~g} / \mathrm{L}$. At the lowest concentration of $0.01 \mathrm{~g} / \mathrm{L}$ both HBP and LP show a peak at about $380 \mathrm{~nm}$. This peak is accompanied by a shoulder at $470 \mathrm{~nm}$ in case of LP, or by additional peak at $470 \mathrm{~nm}$ in case of HBP. With increasing concentration the intensity of PL at $470 \mathrm{~nm}$ increases for both LP and HBP. At the highest concentration, both spectra are dominated by a single peak at $470 \mathrm{~nm}$. These results indicate that the emission at $470 \mathrm{~nm}$ is due to excimer emission from TPA. Excimer formation is more efficient in HBP because of closer proximity between TPA units.

\section{Other Characterizations}

LP and HBP have been further characterized by differental scanning calorimetry (DSC) and cyclic voltammetry (CV).

The glass transition temperature $\left(T_{\mathrm{g}}\right)$ was measured in the range of 50 to $300^{\circ} \mathrm{C}$. LP had $T_{\mathrm{g}}$ of $137^{\circ} \mathrm{C}$, and HBP of $170^{\circ} \mathrm{C}$, respectively. These $T_{\mathrm{g}}$ values compare favourably with low molecular weight compounds where the low $T_{\mathrm{g}}$ is a limitting factor in device applications. ${ }^{30}$ LP and HBP had good thermal stability, showed no melting points and were amorphous.

In general, HBP or dendrimers are easily distinguished from LP upon dissolving in common organic solvents. For the same weights of HBP and LP, more solvent is needed to dissolve LP than HBP. Here, better solubility of HBP has also been confirmed in toluene, chloroform, and THF. For these solvents, the amounts to dissolve LP were 1.5-1.75 times larger that those to dissolve HBP. The polymers are soluble in many other organic solvents and have sufficient stability after film formation.

Charge transport in organic materials is believed to be governed by the hopping process involving redox reaction of charge transport molecules. Cyclic voltammetry $(\mathrm{CV})$ is a routine characterization technique for determining the redox properties of organic and polymeric materials. The characterization is derived from the measurement of current as a function of applied potential obtained in an electrochemical cell.

The redox behavior of LP and HBP was investigated for films cast on a carbon working electrode in dry acetonitrile containing $0.1 \mathrm{M} \mathrm{Bu}_{4} \mathrm{NClO}_{4}$ as an electrolyte, under nitrogen atmosphere. Figure 5 shows cyclic voltammograms of LP and HBP recorded at scanning rate of $2 \mathrm{mV} \mathrm{s}^{-1}$. The redox cycle of LP exhibited a large oxidation wave with a maximum electropotential at $1.0 \mathrm{~V}$ and two small reduction waves at 0.77 and $0.9 \mathrm{~V}$ (Figure 5a). The redox cycle of HBP was more symmetrical and exhibited an oxidation wave at $1.22 \mathrm{~V}$ and a reduction wave at $0.62 \mathrm{~V}$ (Figure $5 \mathrm{~b}$ ). These values were used to calculate the ionization potential (IP) and the electron affinity (EA) for both polymers. For LP, we obtained IP = $5.72 \mathrm{eV}$ and $\mathrm{EA}=2.28 \mathrm{eV}$. The IP value for the HBP was slightly lower at $5.94 \mathrm{eV}$ while the EA was $2.5 \mathrm{eV}$. The CV results indicate that both LP and HBP possess hole transporting ability.

\section{Application to EL Device}

The multilayer EL devices were fabricated using LP or HBP as a hole transport layer and $\mathrm{Alq}_{3}$ as an electron transport and emitting layer. Under forward bias (a positive voltage on the ITO electrode), the current increased with increasing applied voltage (Figure 6), indicating typical rectifying characteristics. The turn-on voltage was about $7 \mathrm{~V}$. The device using HBP showed slightly higher current density at the same voltage. The luminance-voltage $(L-V)$ characteristics of each EL device are shown in Figure 7. The maximum luminance reached $10562 \mathrm{~cd} / \mathrm{m}^{2}$ at $15 \mathrm{~V}$ when LP was used, and $9805 \mathrm{~cd} / \mathrm{m}^{2}$ at $16.5 \mathrm{~V}$ when HBP was used. If we exclude the effect of device preparation, the slightly lower luminance value 

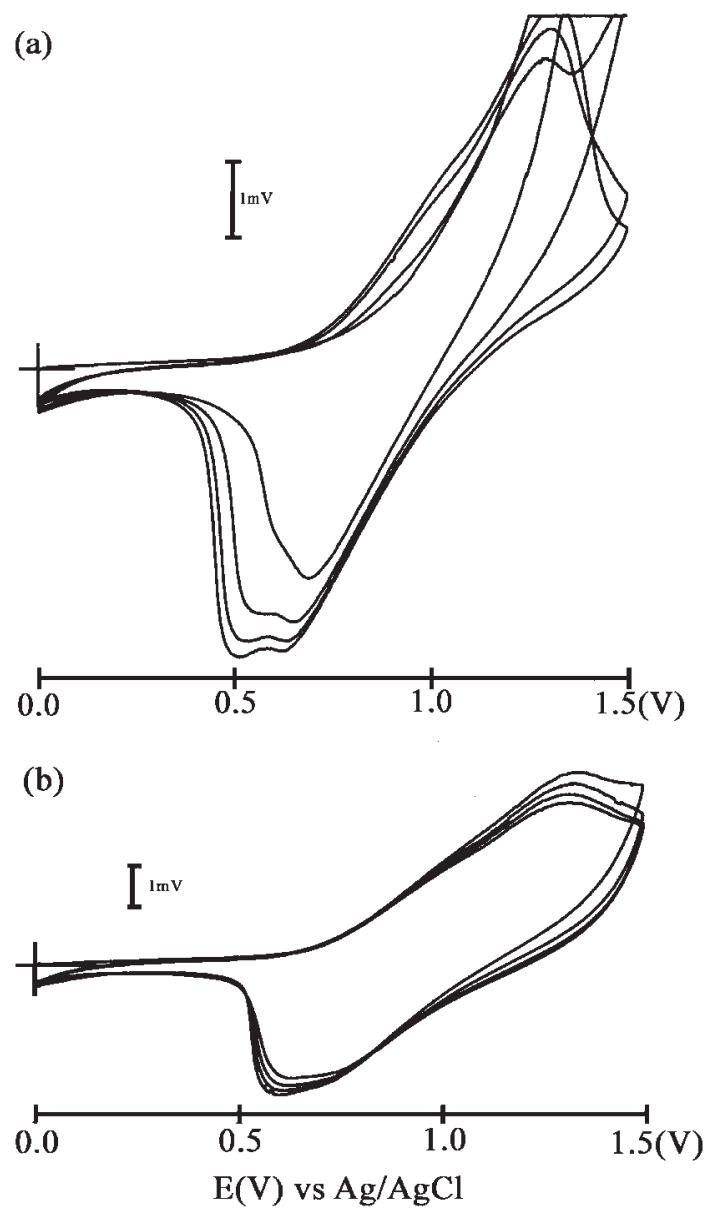

Figure 5. Cyclic voltammograms of polymers: (a) LP, and (b) HBP.

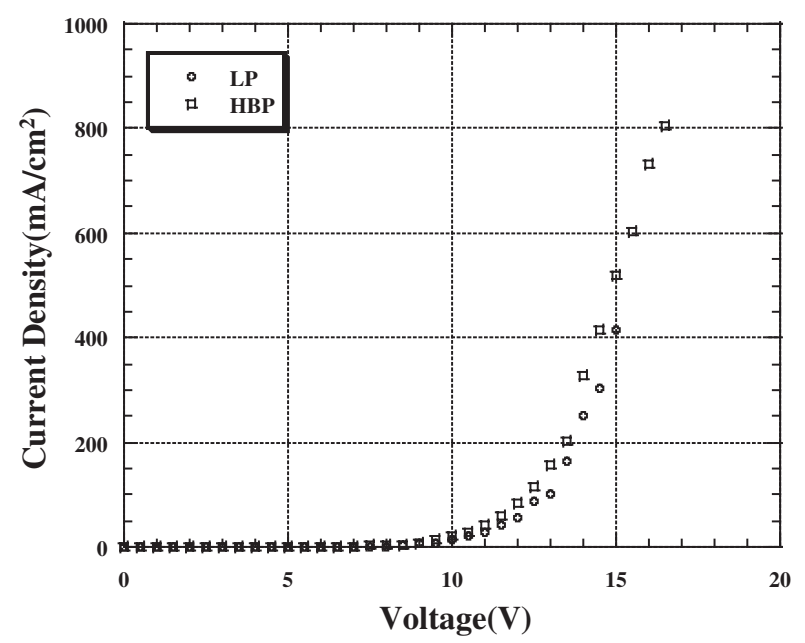

Figure 6. Current-voltage characteristics of ITO/polymer/ $\mathrm{Alq}_{3} / \mathrm{Mg}: \mathrm{Ag}$ EL devices.

of the HBP device could be due to excimer formation. Excimer formation in HBP during EL was confirmed by measuring EL spectra, as shown in Figure 8, where the spectrum of LP shows a single band due to $\mathrm{Alq}_{3}$ emission, while the HBP spectrum is composed of two overlapping bands due to excimer emission at $470 \mathrm{~nm}$ and $\mathrm{Alq}_{3}$ emission at $515 \mathrm{~nm}$. Other reasons

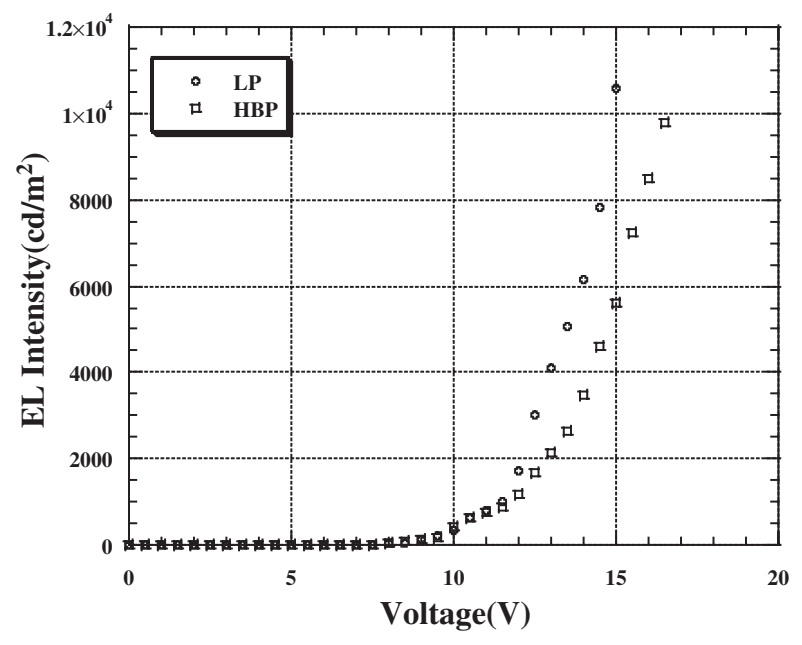

Figure 7. Luminance-voltage characteristics of ITO/polymer/Alq $3 / \mathrm{Mg}: \mathrm{Ag}$ EL devices.

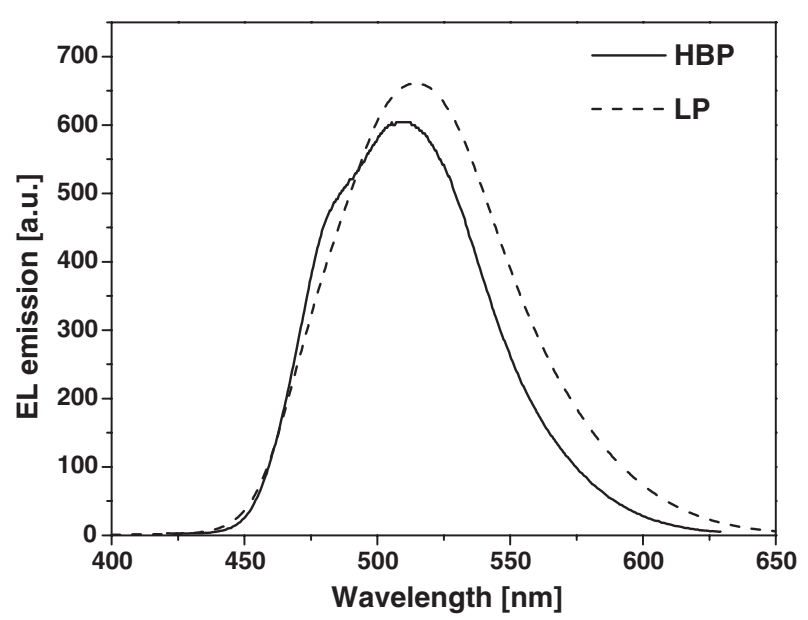

Figure 8. EL emission spectra of LP and HBP.

for the lower luminance of HBP may include lower efficiency of hole injection due to the lower IP value.

\section{CONCLUSIONS}

We have synthesized a novel hyperbranched polymer with triphenylamine (TPA) units by condensation polymerization of TPA- $\mathrm{CH}_{2} \mathrm{OH}\left(\mathrm{AB}_{2}\right.$ type $)$ with core molecules of TPA ( $\mathrm{B}_{3}$ type). The monomer TPA$\mathrm{CH}_{2} \mathrm{OH}$ was added in successive portions to keep the concentration of TPA- $\mathrm{CH}_{2} \mathrm{OH}$ as low as possible, so that the monomer could react only with the end group of the growing chain containing the core. Due to the slow monomer addition and the presence of TPA core molecule, hyperbranched polymer having a narrow molecular weight distribution was obtained. Compared to LP, HBP had higher molecular weight with the same molecular volume. Results of the UV absorption and PL emission spectroscopy revealed that LP and HBP had almost the same UV absorption, but excimer emission of HBP was much more effi- 
cient.

The investigation of electrochemical properties showed that LP and HBP have hole transporting ability. HBP is soluble in common organic solvents and forms thin films with good quality. Their excellent morphological and thermal stability renders them advantageous for electroluminesce applications. Twolayer EL devices of the structure of ITO/polymer/ $\mathrm{Alq}_{3} / \mathrm{Mg}: \mathrm{Ag}$ showed high luminance (of about $10000 \mathrm{~cd} / \mathrm{m}^{2}$ ), indicating excellent hole transporting properties of these polymers.

\section{REFERENCES}

1. W. D. Gill, J. Appl. Phys., 43, 5033 (1972).

2. P. E. Burrows, G. Gu, V. Bulovic, Z. Shen, S. R. Forrest, and M. E. Thompson, IEEE Trans. Electron Devices, 44, 1188 (1997).

3. S. Aratani, T. Kawanishi, and A. Kakuta, Jpn. J. Appl. Phys., 35, 2184 (1996).

4. J. Kido, K. Hongawa, M. Kohda, K. Nagai, and K. Okuyama, Jpn. J. Appl. Phys., 31, L960 (1992).

5. J. Kido, M. Kohda, K. Okuyama, and K. Nagai, Appl. Phys. Lett., 61, 761 (1992).

6. C. Adachi, K. Nagai, and N. Tamoto, Jpn. J. Appl. Phys., 35, 4819 (1996).

7. N. Tamoto, C. Adachi, and K. Nagai, Chem. Mater., 9, 1077 (1997).

8. Y. Yang, Q. Pei, and A. J. Heeger, J. Appl. Phys., 79, 934 (1996).

9. J. Louie, J. F. Hartwig, and A. J. Fry, J. Am. Chem. Soc., 119, 11695 (1997).

10. J. M. Son, Y. Sasaki, K. Ogino, and H. Sato, IEEE Trans. Electron Devices, 44, 1307 (1997).

11. J. Kido, M. Komada, G. Harada, and K. Nagai, Polym. Adv. Technol., 6, 703 (1995).
12. J. Kido, G. Harada, and K. Nagai, Polym. Adv. Technol., 7, 31 (1996).

13. M. Meier, E. Buchwald, and S. Karg, Synth. Met., 76, 95 (1996).

14. A. J. Kraft, J. Chem. Soc., Chem. Commun., 77 (1996).

15. Y. Shirota, in "Organic Light-Emitting Materials and Devices," Z. H. Kafafi, Ed., SPIE 3148, Naval Research Laboratory, Washington, D.C., 1997.

16. X. T. Tao, Y. D. Zhang, T. Wada, H. Sasabe, H. Suzuki, T. Watanabe, and S. Miyata, Adv. Mater., 10, 226 (1998).

17. M. Halim, J. N. G. Pillow, and I. D. W. Samuel, Adv. Mater., 11, 371 (1999).

18. D. A. Tomalia, A. M. Naylor, and W. A. Goodard, Angew. Chem., Int. Ed. Engl., 29, 138 (1990).

19. Y. H. Kim, J. Polym. Sci., Part A: Polym. Chem., 36, 1685 (1998).

20. B. Voit, J. Polym. Sci., Part A: Polym. Chem., 38, 2505 (2000).

21. J. M. J. Fréchet, M. Henmi, I. Gitsov, S. Aoshima, M. R. Leduc, and R. B. Grubbs, Science, 269, 1080 (1995).

22. C. J. Hawker, Adv. Polym. Sci., 147, 113 (1999).

23. S. H. Park, K. Ogino, and H. Sato, Polym. Adv. Technol., 11, 349 (2000).

24. K. Strzelec, N. Tsukamoto, J. Ha, and H. Sato, Polym. Int., 50, 1228 (2001).

25. W. Radke, G. Litvinenko, and A. H. E. Müller, Macromolecules, 31, 239 (1998).

26. U. Beginn, C. Drohmann, and M. Möller, Macromolecules, 30, 4112 (1997).

27. R. Habselmann, D. Holter, and H. Frey, Macromolecules, 31, 3700 (1998).

28. J. M. Son, M. Nakao, K. Ogino, and H. Sato, Macromol. Chem. Phys., 200, 65 (1999).

29. J. M. Son, T. Mori, K. Ogino, H. Sato, and Y. Ito, Macromolecules, 32, 4849 (1999).

30. S. Tokito and Y. Taga, Appl. Phys. Lett., 66, 673 (1995). 